\title{
Monitoring and Discrimination of Plant Disease and Insect Pests based on agricultural IOT
}

\author{
X. F. Wang ${ }^{1}$, Z. Wang ${ }^{1}$, S.W. Zhang ${ }^{1}$, Y. Shi ${ }^{1}$ \\ ${ }^{1}$ XiJing University, Xi'an Shanxi 710123, China
}

KEYWORD: Plant disease and insect pests; Agriculture Internet of things (IOT); monitoring discriminant model; data mining and information fusion.

ABSTRACT: How to establish a monitoring and discriminant model based on agriculture Internet of things (IOT) for plant disease and insect pests is a main topic. In this paper, we study the establishment of monitoring discriminant model by data mining and information fusion algorithm. Focus on the application of association rule mining and fuzzy reasoning information fusion in the monitoring plant disease and insect pests. Using environment information and the Apriori algorithm, a model is proposed to realize the real-time monitoring system of environmental parameters and the occurrence of plant diseases and insect pests.

\section{Introduction}

Plant diseases and insect pests seriously affect the normal growth of plants, the yield and quality of agricultural products [1-4]. In recent years, with the dramatic changes in climate, the natural environment of the plant growth has been damaged by pollution, frequent natural disasters, as well as the development of agricultural production. The farming model is broken in the way of cultivation and the control measures of plant disease and insect pests, the harm is more and more serious, and its scope and extent seriously restricts the production of agriculture and sustainable development. The Internet of things (IOT) is a very good system framework for plant diseases and insect pests [5-8]. In the field of plant protection, the use of IOT can automatically detect and record the regional micro climate information, temperature, humidity, moisture, and more information related to environmental information and to acquisition of plant disease leaf images [9-10]. Combined with the plant protection expert system, we can accurately predict the occurrence and development of plant diseases and insect pests. Due to many kinds of plant disease and insect pests and a variety of leaf symptoms resulted by many diseases and insect pests, the current remote monitoring and control system of plant disease and insect pests based on IOT still exist many problems to be solved. In this paper, based on IOT, we study the remote monitoring and control model of plant disease and insect pests. The research result will support the development agricultural informatization.

\section{Agricultural IOT and precision agriculture}

Agricultural IOT technology is a kind of network [11], by the radio frequency identification (RFID) technology, infrared sensors, laser scanner, GPS global positioning system information sensing equipment, according to the agreement, which combine the Internet with any products to implement the information communication and exchange, and to realize intelligent identification, location, tracking, monitoring and management. The basic features of IOT are comprehensive perception, reliable transmission, intelligent processing. Overall perception refers to the object information acquisition and acquisition at anytime and anywhere by RFID technology, two-dimensional code, GPS, camera, sensor networks, etc. Reliable delivery is the fusion of various communication networks through the Internet, the object access information network, and at any time to carry out of reliable information sharing and interaction. Intelligent processing refers to cloud computing and fusion recognition and intelligent computer technology, which can enhance the insight on economy, society and all kinds of changes in the physical world and activities, realize intelligent control and decision.

Precision agriculture is the main development direction of the world agriculture in the 21 Century. In the United States, Canada and other developed countries, precision agriculture has become an important way for the sustainable development of agriculture by combining a high-new technology and agricultural production industry. Sensor nodes are deployed in farmland in the target area, network 
node of a large number of accurate, real-time temperature information collection, humidity, gas concentration, light according to the intensity of environmental information, the environment information in data aggregation node collection, network of collection environment information of theoretical analysis, to help producers improve agricultural production efficiency, promote the efficient management of agricultural disease and insect pest, realize the reasonable and efficient utilization of precise management and land resources of agricultural modernization. The important component of IOT is the wireless sensor network. The soil moisture information acquisition can meet the requirements of the continuous, rapid, and accurate measurement. Wireless sensor network as a new information acquisition and processing technology, with its low cost, low power consumption, high reliability and other characteristics, has gradually penetrated into the agricultural field.

\section{Agriculture IOT environment information fusion monitoring discriminant model}

First of all, we collect a variety of environmental information by many sensors to realize the data integration of heterogeneous database and information extraction, then structure a variety of environmental information and the data from other database, and mining the typical association rules, and transfer them to processing central of fuzzy reasoning information fusion, response the state of the farmland environment by decision level fusion classification. Finally, the monitoring results are sent to the user interface, which can monitor the environmental situation of farmland. Among them, the information fusion layer can get all kinds of environmental information and monitoring results of the association rules by the Apriori algorithm. Then, the real-time environmental information is used as the input of fuzzy reasoning and information fusion. The association rule is used as the rule of fuzzy reasoning and information fusion. Finally, according to the monitoring results, the corresponding control strategy is formulated.

The realization of fuzzy inference algorithm can directly achieve by the Fuzzy toolbox of Matlab, the process is as follows:

Creating a Fuzzy Inference System FIS objection,

fis=newfis(fisName, fisType, andMethod, orMethod, impMethod, aggMethod, defuzzMethod)

In the function, the first parameter is usually only provided, and the other following parameters are default.

Increasing the fuzzy variable language,

fis= addvar(fts, 'varType', 'varName', varBounds)

The fuzzy variable is defined as the input and output of the two categories. Each time the fuzzy variable is added, it will be assigned an index in order to use the variable.

Increasing the name of fuzzy variable language,

fis = addmf(fis, 'varType', varlndex', 'mfName', 'mfType', mfParams)

Increase the name of the fuzzy variable language (or the fuzzy set), each fuzzy language name is subject to a vague language. Among of them, each parameter represents the membership function, which can be expressed as: trimf as triangle function, rmpm as trapezoidal function, gajmw as Gauss functions, or can also be a custom function. Each language name also corresponds to an index, in order to increase the order obtained.

(4) Increase control rules (or the rule of fuzzy reasoning),

Fis $=$ addrule(fis, ruleList)

ruleList is a matrix, and each line represents a rule. Suppose fis has $\mathrm{n}$ inputs and $\mathrm{m}$ outputs, then each line has $n+m+2$ elements, the first $n$ numbers respectively the $n$ input variables of the language name index, the last $m$ numbers respectively express $m$ output variables of the language name index, the last two numbers respectively express the rule weights and condition.

(5) When the input is given, the output is obtained, and the fuzzy inference is obtained as

Output=evalfis(input, fismat).

where fismat is the first built FIS object. 
Table1 Original environmental information data

\begin{tabular}{|c|c|c|c|c|c|}
\hline No. & precipitation & $\begin{array}{c}\text { CO2 concentra- } \\
\text { tion }\end{array}$ & humidity & temperature & $\begin{array}{c}\text { monitoring re- } \\
\text { sults }\end{array}$ \\
\hline 1 & 86.3 & 16.1 & 31.4 & 1.4 & 99 \\
\hline 2 & 150.2 & 17.6 & 32.3 & -1.0 & 132 \\
\hline 3 & 307.1 & 14.2 & 97.4 & -0.9 & 284 \\
\hline 4 & 234.8 & 15.9 & 31.1 & 1.4 & 137 \\
\hline 5 & 230.0 & 15.0 & 27.0 & 1.4 & 256 \\
\hline 6 & 72.2 & 15.9 & 29.3 & 4.0 & 38 \\
\hline 7 & 170.2 & 14.3 & 73.0 & -0.8 & 232 \\
\hline 8 & 94.0 & 16.2 & 3.5 & 3.8 & 102 \\
\hline 9 & 150.0 & 16.2 & 16.5 & -0.1 & 410 \\
\hline 10 & 12.1 & 17.7 & 27.3 & 2.7 & 198 \\
\hline
\end{tabular}

Table 2 the discretization level classification

\begin{tabular}{|c|c|c|c|c|c|}
\hline level & $\begin{array}{c}\text { precipita- } \\
\text { tion }\end{array}$ & $\begin{array}{c}\mathrm{CO} 2 \text { concen- } \\
\text { tration }\end{array}$ & $\begin{array}{c}\text { humidi- } \\
\text { ty }\end{array}$ & $\begin{array}{c}\text { tempera- } \\
\text { ture }\end{array}$ & $\begin{array}{c}\text { monitoring } \\
\text { results }\end{array}$ \\
\hline 1 & $\mathrm{P}>100.0$ & $\mathrm{C}<14.8$ & $\mathrm{H}<25$ & $\mathrm{~T}<0.1$ & $\mathrm{R}<130$ \\
\hline 2 & $100<\mathrm{P} \leq 160$ & $14.8<\mathrm{C} \leq 15.5$ & $\begin{array}{c}25<\mathrm{H} \leq \\
40\end{array}$ & $0.1<\mathrm{T} \leq 1.5$ & $131<\mathrm{R} \leq 224$ \\
\hline 3 & $160<\mathrm{P} \leq 250$ & $15.6<\mathrm{C} \leq 16$ & $\begin{array}{c}40<\mathrm{H} \leq \\
75\end{array}$ & $1.6<\mathrm{T} \leq 3$ & $225<\mathrm{R} \leq 317$ \\
\hline 4 & $\mathrm{P}>250$ & $>16$ & $\mathrm{H}>75$ & $\mathrm{~T}>3$ & $\mathrm{R}>317$ \\
\hline
\end{tabular}

\begin{tabular}{|c|c|c|c|c|c|}
\hline No. & $\begin{array}{c}\text { precipita- } \\
\text { tion }\end{array}$ & $\begin{array}{c}\text { CO2 concen- } \\
\text { tration }\end{array}$ & $\begin{array}{c}\text { humid- } \\
\text { ity }\end{array}$ & $\begin{array}{c}\text { tempera- } \\
\text { ture }\end{array}$ & $\begin{array}{c}\text { monitoring re- } \\
\text { sults }\end{array}$ \\
\hline 1 & 1 & 4 & 2 & 2 & 1 \\
\hline 2 & 2 & 4 & 2 & 1 & 2 \\
\hline 3 & 4 & 1 & 4 & 1 & 3 \\
\hline 4 & 3 & 3 & 2 & 2 & 2 \\
\hline 5 & 3 & 2 & 2 & 2 & 3 \\
\hline 6 & 1 & 3 & 2 & 4 & 1 \\
\hline 7 & 2 & 4 & 1 & 1 & 4 \\
\hline 8 & 3 & 1 & 3 & 1 & 3 \\
\hline 9 & 1 & 4 & 1 & 4 & 1 \\
\hline 10 & 1 & 4 & 2 & 3 & 2 \\
\hline
\end{tabular}

By the Apriori algorithm, the association rules with the minimum support threshold and the minimum trust threshold are obtained. The monitoring experiments by Matlab are implemented, and compare with that of the actual monitoring results. The experiment results are shown in Table 4. The correct rate is more than $80 \%$.

Table 4 the discretization of the Table1.

\begin{tabular}{|c|c|c|c|c|c|c|}
\hline No. & $\begin{array}{c}\text { precipita- } \\
\text { tion }\end{array}$ & $\begin{array}{c}\text { CO2 concen- } \\
\text { tration }\end{array}$ & $\begin{array}{c}\text { humid- } \\
\text { ity }\end{array}$ & $\begin{array}{c}\text { tempera- } \\
\text { ture }\end{array}$ & $\begin{array}{c}\text { monitoring re- } \\
\text { sults }\end{array}$ & $\begin{array}{c}\text { fusion re- } \\
\text { sults }\end{array}$ \\
\hline 11 & 83.0 & 17.0 & 2.09 & 3.4 & $128 / 1$ & $70.4465 / 1$ \\
\hline 12 & 127.7 & 17.6 & 1.5 & 2.2 & $223 / 2$ & $86.5693 / 1$ \\
\hline 13 & 250.0 & 14.6 & 80.5 & 0.2 & $267 / 3$ & $286.4287 / 3$ \\
\hline 14 & 87.0 & 17.2 & 20.9 & -0.5 & $130 / 1$ & $116.4231 / 1$ \\
\hline 15 & 232.0 & 14.5 & 32.5 & 1.4 & $312 / 3$ & $285.8606 / 3$ \\
\hline
\end{tabular}

\section{Conclusions}

Plant diseases and insect pests are the key problems in the plant cultivation, soil environment, climate condition and cultivation technology create different conditions for the survival of the plant diseases and insect pests. So to monitor, forecast accurately and timely of the occurrence of plant disease and insect pests, then make up comprehensive prevention and control plan to take necessary measures reducing the occurrence of plant disease and insect pests, is very important to ensure the quality of 
high quality products. In order to improve the overall level of agricultural disease and insect pest prevention and cure, intelligent monitoring system for agricultural disease and insect pest based on IOT is studied in this paper. The association rules of various environmental information and monitoring results are obtained by Apriori. Then, the real-time environmental information is used as the input of fuzzy reasoning and information fusion. The association rule is used as the rule of fuzzy reasoning and information fusion. Finally, according to the monitoring results, the corresponding control strategy is formulated. The experimental results show that the recognition rate of the environmental monitoring and recognition rate is $80 \%$, which has good agricultural monitoring value and wide application prospect.

\section{Acknowledgement}

The authors would like to thank the anonymous reviewers for their critical and constructive comments and suggestions. This work is partially supported by China National Natural Science Foundation under grant No. 61473237. It is also supported by the Shaanxi provincial education department Foundation under grant No. 2013JK1145. The authors would like to thank all the editors and anonymous reviewers for their constructive advices. This work is also supported by the grants of the higher education development special fund of Shaanxi Private (XJ13ZD01) and the basic research project of Natural Science of Shaanxi Province (2014JM2-6096).

\section{References}

[1] Dheeb Al Bashish, Malik Braik, Sulieman Bani-Ahmad. Detection and Classification of Leaf Diseases using K-means-based Segmentation and Neural-networks-based Classification [J]. Information Technology Journal, 2011, 10: 267-275.

[2] Piyush Chaudhary, Anand K. Chaudhari, Dr. A. N. Cheeran. Color Transform Based Approach for Disease Spot Detection on Plant Leaf [J]. International Journal of Computer Science and Telecommunications,2012,3(6):65-70.

[3] T. Rumpf, A. K. Mahlein, U. Steiner, et al. Early detection and classification of plant diseases with Support Vector Machines based on hyperspectral reflectance [J].Computers and Electronics in Agriculture, 2010:74:91-99.

[4] H Al-Hiary, S Bani-Ahmad, M Reyalat, et al. Article: Fast and Accurate Detection and Classification of Plant Diseases[J]. International Journal of Computer Applications, 2011,17(1):31-38.

[5] Luigi Atzori, Antonio Iera, Giacomo Morabito[D]. The Internet of Things: A Survey. Computer Networks, 2010(54): 2787-2805.

[6] Thiago Teixeira, Sara Hachem, Valerie Issarny, Nikolaos Georgantas[C]. Service Oriented Middleware for the Internet of Things: A Perspective. Service Wave, LNCS,2011, 6994:220-229.

[7] Luis Ruiz-Garcia, Loredana Lunadei. The role of RJFID in agriculture: Applications, limitations and challenges [J].Computers and Electronics in Agriculture, 2011, 79(1):42-50

[8] Wen-Tsai Sung, Ming-Han Tsai. Data fusion of multi-sensor for IOT precise measurement based on improved PSO algorithms [J]. Computers and Mathematics with Applications, 2012,64:1450146

[9] Taylor K, Griffith C, Lefort L, Gaire R, et al.Farming the Web of Things[C]. Intelligent Systems, IEEE, 2013:12-19.

[10]Meonghun Lee, Jeonghwan Hwang, Hyun Yoe. Agricultural Production System Based on IOT [C]. 16th International Conference on Computational Science and Engineering, 2013:833-837

[11]Maiirya B, Beg M R, Mxjkheijee S. Expert system design and architecture for farming sector[C]. IEEE Conference on Information \& Communication Technologies 2013:10-15. 